\title{
Absent in Melanoma 2 (AIM2) limits pro-inflammatory cytokine transcription in cardi- omyocytes by inhibiting STAT1 phosphorylation
}

\author{
Antonia Furrer ${ }^{\mathrm{a}}$, Michael O. Hottiger ${ }^{\mathrm{a}}$, and Alan Valaperti ${ }^{\mathrm{a},{ }^{*}}$
}

${ }^{a}$ Department of Molecular Mechanisms of Disease, University of Zurich, Winterthurerstrasse 190, 8057 Zurich, Switzerland

Running title: AIM2 limits inflammation in cardiomyocytes ${ }^{1}$

* To whom correspondence should be addressed:

Alan Valaperti, Ph.D.

Department of Molecular Mechanisms of Disease

University of Zurich

Winterthurerstrasse 190

8057 Zurich

Switzerland

Tel.: +41-44-635-5476

E-mail: alan.valaperti@vetbio.uzh.ch or alan.valaperti@me.com

${ }^{1}$ Abbreviations: AIM2, absent in melanoma 2; NLRP3, NACHT, LRR and PYD domains-containing protein 3; NLRC4, NLR family CARD domain-containing protein 4; TLR, toll-like receptor; LPS, lipopolysaccharide; IFN- $\gamma$, interferon gamma; IL-6, interleukin-6; IP-10, interferon gamma-induced protein 10; TNF- $\alpha$, tumor necrosis factor alpha; NF- $\mathrm{B}$, nuclear factor kappa-light-chain-enhancer of activated B cells; STAT1, signal transducer and activator of transcription 1. 


\begin{abstract}
Interferon (IFN)- $\gamma$ is highly upregulated during heart inflammation and enhances the production of pro-inflammatory cytokines. Absent in Melanoma 2 (AIM2) is an IFN-inducible protein implicated as a component of the inflammasome. Here we seek to determine the role of AIM2 during inflammation in cardiac cells.

We found that the presence of AIM2, but not of the other inflammasome components Nodlike receptor (NLR) NLRP3 or NLRC4, specifically limited the transcription of the proinflammatory cytokines interleukin (IL)-6, IP-10, and tumor necrosis factor (TNF)- $\alpha$ in HL-1 mouse cardiomyocytes stimulated with IFN- $\gamma$ and lipopolysaccharides (LPS). Similarly, AIM2 reduced pro-inflammatory cytokine transcription in primary mouse neonatal cardiomyocytes (MNC), but not in primary mouse neonatal cardiac fibroblasts (MNF). Interestingly, AIM2dependent reduction of pro-inflammatory cytokines in cardiomyocytes was independent of Caspase-1. Mechanistically, AIM2 reduced pro-inflammatory cytokine transcription in cardiomyocytes by interacting with and inhibiting the phosphorylation of STAT1. In AIM2-depleted cardiomyocytes, increased STAT1 phosphorylation enhanced the NF- $\kappa$ B pathway by promoting NF$\kappa \mathrm{B}$ p65 phosphorylation and acetylation.
\end{abstract}

These results show for the first time that AIM2 plays an important anti-inflammatory, yet inflammasome-independent function in cardiomyocytes. Our findings will help to further understand how the various heart cell types differently react to inflammatory stimuli.

Key words: NF-кB p65; STAT1; Cardiomyocytes; Interferon- $\gamma$; Interleukin-6. 


\section{Introduction}

Absent in Melanoma 2 (AIM2) is a member of the IFN-inducible HIN-200 family and was first discovered as a suppressor of colon cancer (Choubey et al., 2010). AIM2 is an inflammasome sensor that oligomerizes with the adaptor molecule ASC and pro-Caspase-1, thereby contributing to pro-Caspase- 1 cleavage, IL- $1 \beta$ activation, IL-18 production, and ultimately to cell death (pyroptosis) (Burckstummer et al., 2009; Fernandes-Alnemri et al., 2009; FernandesAlnemri et al., 2010; Hornung et al., 2009). However, AIM2 has also been shown to protect from colorectal cancer development and from the autoimmune disease systemic lupus erythematous in an inflammasome (i.e. Caspase-1)- and IL-1 $\beta$-independent manner (Man et al., 2015; Panchanathan et al., 2010; Wilson et al., 2015). AIM2 protein expression is increased in macrophages upon IFN- $\gamma$ stimulation (Veeranki et al., 2011). Since heart-infiltrating immune cells produce large amounts of IFN- $\gamma$ during heart inflammation (Fairweather et al., 2004; Han et al., 2012; Rangachari et al., 2006), AIM2 may potentially be highly expressed in cardiac cells.

Excessive or prolonged stress and cardiac damage during heart inflammation promotes inappropriate host responses that result in dilated cardiomyopathy (DCM), which ultimately leads to lethal chronic heart failure (Krum and Abraham, 2009). Acute myocardial inflammation is mainly triggered by stimulation of Toll-like receptors (TLRs), by damage-associated molecular patterns (DAMPs) and/or by pathogen-associated molecular patterns (PAMPs), and enhanced by inflammatory cytokines (Mann, 2011). Clinical and experimental evidence suggests that sustained IFN- $\gamma$ production is harmful for the heart, promoting the progression from acute to chronic heart inflammation. Indeed, in patients with heart failure, serum levels of IFN- $\gamma$ are significantly higher than those in healthy controls (Cheng et al., 2009; Cheng et al., 2005b). Furthermore, transgenic mice over-expressing IFN- $\gamma$ spontaneously develop chronic heart inflammation (Reifenberg et al., 2007), rats with experimental acute myocardial infarction (AMI) show enhanced IFN- $\gamma$ - 
dependent heart inflammation (Cheng et al., 2005a), and addition of recombinant IFN- $\gamma$ to rat cardiac cells reduces their activity (Hellkvist et al., 2002).

Recent findings demonstrate that IFN- $\gamma$ augments TLR-induced transcription of the proinflammatory cytokines IL-6 and TNF- $\alpha$ (Qiao et al., 2013), which are known to worsen the outcome of myocardial infarction and myocarditis in experimental animal models (Eriksson et al., 2003; Kobara et al., 2010; Kubota et al., 1997; Sun et al., 2007). IFN- $\gamma$ is the major trigger of STAT1 phosphorylation and homo-dimerization, which lead to STAT1 nuclear translocation (Hu and Ivashkiv, 2009). STAT1 has been shown to increase the severity of experimental myocardial infarction and ischemia/reperfusion injury (McCormick et al., 2012; Stephanou, 2004), while antioxidant flavonoids protect from ischemia/reperfusion-induced damage by down-regulating the activation of STAT1 (Townsend et al., 2004). STAT1 facilitates and prolongs the recruitment of NF- $\kappa \mathrm{B}$ p65 to the promoters and enhancers of IL-6 and TNF- $\alpha$. To properly initiate IL-6 and TNF- $\alpha$ transcription, NF- $\kappa \mathrm{B}$ p65 undergoes post-translational modifications, such as serine phosphorylation and lysine acetylation (Buerki et al., 2008; Ghosh and Hayden, 2008). Upon

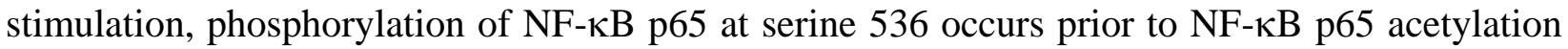
at lysine 310, which is required for transcriptional activation of pro-inflammatory cytokines (Chen et al., 2005; Nwachukwu et al., 2014). Consistently, deacetylation of NF-кB p65 at lysine 310 by SIRT1 or HDAC3 inhibits expression of inflammatory genes (Buerki et al., 2008; Rothgiesser et al., 2010). The activation of the NF- $\mathrm{KB}$ signaling pathway is known to result in acute heart failure (Boyd et al., 2006).

Cardiomyocytes and cardiac fibroblasts express inflammatory cytokines and chemokines, such as IL-6, TNF- $\alpha$, and CXCL2 (Aoyagi and Matsui, 2011; Boyd et al., 2006; Brown and Jones, 2004; Sandanger et al., 2013; Turner et al., 2007), thus initiating inflammatory responses. However, recent findings have shown that cardiomyocytes and cardiac fibroblasts can also respond 
differently to the same inflammatory stimulus. Indeed, upon IL-17A stimulation, cardiomyocytes do not respond by activation of the NF- $\kappa \mathrm{B}$ pathway, while cardiac fibroblasts produce high levels of inflammatory cytokines and chemokines, such as IL-6, GM-CSF, and CXCL1 (Wu et al., 2014). In addition, LPS stimulation leads to inflammasome activation in cardiac fibroblasts, but not in cardiomyocytes (Kawaguchi et al., 2011), while only cardiac fibroblast, but not cardiomyocytes, produce increased levels of IL-6 and TNF- $\alpha$ after Coxsackievirus B3 (CVB3) infection (Lindner et al., 2014). However, when ATP or nigericin are used to stimulate cardiomyocytes, they can activate the inflammasome in a Caspase-1- and pyroptosis-dependent manner, but do not produce IL-1 $\beta$ (Marchetti et al., 2015; Mezzaroma et al., 2011; Takahashi, 2014).

Since a role for AIM2 in IFN- $\gamma$-dependent cardiac cell inflammation has not yet been elucidated, we investigated whether AIM2 influences the sensitivity of cardiomyocytes to IFN- $\gamma$ triggered inflammatory stimuli and the potential molecular mechanism behind AIM2 regulation. Using the well-established cardiomyocyte cell line HL-1 and primary cardiomyocytes, we were able to demonstrate a novel anti-inflammatory function of AIM2 in cardiac cells. 


\section{Materials and Methods}

\subsection{Cell culture experiments and cell stimulation}

One-day old wild-type newborn mice were used to isolate primary mouse neonatal ventricular cardiomyocytes (MNC) and primary mouse neonatal ventricular fibroblasts (MNF), as previously described (Valaperti et al., 2014). Briefly, heart ventricles were minced in small pieces and then digested with trypsin $(0.8 \mathrm{mg} / \mathrm{ml})$. Ventricular cell suspensions were plated for two hours at $37^{\circ} \mathrm{C}$ to separate cardiac fibroblasts from cardiomyocytes. Attached cells were used as MNF, while cells in suspension were considered MNC and then cultivated in the presence of BrdU to reduce the proliferation of cardiac fibroblasts. HL-1 mouse cardiomyocytes were cultivated in supplemented Clyacomb medium. H9C2 rat cardiomyoblasts (kindly provided by Dr. A. Radenovic and Drs. L. Liaudet and J. Lugrin), RAW mouse monocytes, 3 T3 mouse fibroblasts, and HEK293 human embryonic kidney cells were cultivated in supplemented DMEM medium. IFN- $\gamma$ and TNF- $\alpha$ (both Peprotech) were used at a final concentration of $10 \mathrm{ng} / \mathrm{ml}$. LPS (Sigma-Aldrich) was used at a final concentration of $0.5 \mu \mathrm{g} / \mathrm{ml}$. MG132 (Sigma-Aldrich) was used at a final concentration of $10 \mu \mathrm{M}$.

\subsection{HL-1 cells}

HL-1 cells were maintained in Claycomb medium (Sigma) supplemented with $2 \mathrm{mM}$ Lglutamine (Gibco), $0.1 \mathrm{mM}$ norepinephrine (Sigma), 1:100 penicillin/streptomycin (Sigma), and

$10 \%$ fetal bovine serum (Gibco) in a $5 \% \mathrm{CO}_{2}$ incubator at $37^{\circ} \mathrm{C}$. They were expanded in $75 \mathrm{~cm}^{2}$ flasks pre-coated with $5 \mu \mathrm{g} / \mathrm{ml}$ fibronectin (Sigma) and $0.02 \%$ gelatin (Sigma) and passaged before reaching full confluence. 


\subsection{Plasmids and transfection}

pEGFP-C2-AIM2 and pCMV6-AIM2-FLAG vectors were produced by cloning PCR-generated full-length AIM2 in XhoI and SacII sites and in HindIII and XhoI sites, respectively. STAT1, STAT4, STAT5 $\alpha$, and STAT5 $\beta$ vectors were purchased from Addgene. Transfection into HEK293 cells was performed with the calcium phosphate precipitation method as previously described (Buerki et al., 2008). For HL-1 transfection, 4 x $10^{5}$ cells were plated in 12-well plate with $1 \mathrm{ml}$ Claycomb medium without norepinephrine and penicillin/streptomycin. Two $\mu \mathrm{g}$ of DNA were transfected with Lipofectamine 2000 (Invitrogen) according to the manufacturer's protocol.

\section{4. siRNA transfection}

AIM2, NLRP3, NLRC4, Caspase-1, and STAT1 siRNAs were purchased from Qiagen. For transfection, $1 \times 10^{5}$ cells were plated in 12-well plate with $1 \mathrm{ml}$ supplemented Claycomb medium. Twenty-five pmol siRNA were transfected with RNAiMAX (Invitrogen) according to the manufacturer's protocol.

\subsection{Cellular fractionation}

Cultivated cells were harvested, washed, and gently resuspended in cell lysis buffer (10 mM Hepes, pH 7.9, $10 \mathrm{mM} \mathrm{KCl,} 1.5 \mathrm{mM} \mathrm{MgCl} 2,0.1 \%$ NP-40, 5 mM DTT, $1 \mathrm{mM} \mathrm{PMSF,} 1 \mu \mathrm{g} / \mathrm{ml}$ pepstatin, $1 \mu \mathrm{g} / \mathrm{ml}$ leupeptin, $1 \mu \mathrm{g} / \mathrm{ml}$ bestatin) for $5 \mathrm{~min}$ on ice. After centrifugation at 2,500 $\mathrm{g}$ for $5 \mathrm{~min}$, supernatant was collected as cytoplasmic fraction, while the nuclear pellet was washed twice in cell lysis buffer without NP-40. Nuclear fraction was resuspended in nuclear extraction buffer (20 mM Hepes, pH 7.9, $1.5 \mathrm{mM} \mathrm{MgCl}_{2}, 420 \mathrm{mM} \mathrm{NaCl}, 25 \%$ glycerol, $5 \mathrm{mM}$ DTT, $1 \mathrm{mM}$ 
PMSF, $1 \mu \mathrm{g} / \mathrm{ml}$ pepstatin, $1 \mu \mathrm{g} / \mathrm{ml}$ leupeptin, $1 \mu \mathrm{g} / \mathrm{ml}$ bestatin), vortexed and then centrifuged at $12,000 \mathrm{~g}$ for $10 \mathrm{~min}$. Supernatants were collected as nuclear fraction.

\subsection{Immunofluorescence staining}

HEK293 and HL-1 cells were fixed with 4\% paraformaldehyde and then permeabilised with $0.2 \%$ Triton X. Cells were blocked with PBS containing $1 \%$ BSA and $0.2 \%$ Triton X. Anti-NF$\kappa \mathrm{B}$ p65 antibody $(1: 250)$ was incubated overnight at $4^{\circ} \mathrm{C}$. Secondary anti-rabbit AlexaFluor488 or Cy3 antibodies (1:250) were incubated at room temperature. Vectashield counting solution (Vector Laboratories) with DAPI was used to cover the slides. Cells were observed with a Leica fluorescent microscope.

\subsection{Quantitative RT-PCR (qRT-PCR) and semi-quantitative RT-PCR}

RNA was isolated with Trizol Reagent (Invitrogen) according to the manufacturer's protocol. Reverse transcription was performed with $1 \mu \mathrm{g}$ RNA. The $2^{-\Delta \Delta \mathrm{Ct}}$ method was used for qRT-PCR gene transcription analysis. Semi-quantitative RT-PCR was performed with the cDNA produced from $1 \mu \mathrm{g}$ RNA. Resulting cDNA ran for 30 cycles, and genes of interest were compared with the housekeeping gene GAPDH.

\subsection{Western Blotting and Immunoprecipitation}

Tissue or cell lysates were separated by $10 \%$ SDS-Bis-Tris gel electrophoresis, transferred on a PVDF membrane (Millipore), and then probed with specific antibodies to indicated proteins. IRdye-conjugated secondary antibodies were used to detect bands with a LICOR Odyssey scanning platform. Bands densitometry was evaluated with the GelEval software. For detection of phosphorylated JAK1 and JAK2, the $\mathrm{Mn}^{2+}$ Phos-tag Acrylamide (Wako) was used according to the 
manufacturer's protocol. For immunoprecipitation of FLAG-tagged AIM2 proteins, FLAG antibodies (Sigma-Aldrich) were coupled to Dynabeads Protein G (Invitrogen) and immunoprecipitated following the manufacturer's protocol.

\subsection{Reagents and Antibodies}

The AIM2 antibody was a kind gift from Dr. Teresa Fernandes-Alnemri, Thomas Jefferson University, Philadelphia. Antibody to rat AIM2 was purchased from eBioscience. Antibodies to STAT1, phosphorylated-STAT1 (P-STAT1), JAK1, JAK2, and phosphorylated NF-кB p65, were

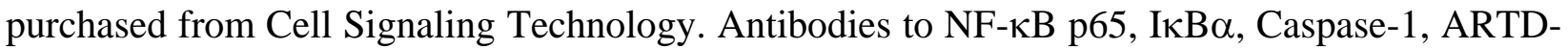
1, and GAPDH were purchased from Santa Cruz Biotechnology. Antibodies to tubulin and FLAG were purchased from Sigma-Aldrich. Antibody to HA was purchased from Covance. Specific antibody to NF-kB p65 acetylated lysine 310 was generated in collaboration with Abcam.

\subsection{Statistics}

Data from different treatment groups were analyzed with 2-way ANOVA and Bonferroni post hoc testing. Data are presented as mean with standard deviation. Statistical analysis was conducted with the use of Prism 5 software (GraphPad Software). Data are expressed as mean \pm standard deviation (s.d.). Differences were considered to be statistically significant for $p<0.05$. 


\section{Results}

\subsection{Transcription of pro-inflammatory cytokines in synergistically stimulated heart cells}

We first aimed to figure out if Aim2 expression levels were different before and after induction of heart disease in experimental mouse models. Interestingly, we observed that upon induction of viral myocarditis with the Coxsackievirus B3 (CVB3), Aim2 RNA transcription was reduced in the heart and spleen (day 4) (Suppl. Fig. S1A). In addition, AIM2 proteins in the heart were also decreased at days 4 and 7 (Suppl. Fig. S1B). This corresponds to the time point when the virus is most active and detrimental (Valaperti et al., 2014) and the host inflammatory immune response in the heart is at its peak (Suppl. Fig. S1C). Upon induction of myocardial infarction, Aim2 RNA transcription was reduced in the infarct zone at day 1 and 3, which was correlated with increased transcription of the pro-inflammatory cytokines Il-6, Ip-10, and Tnf- $\alpha$ (Suppl. Fig. S1D and E). These results show that AIM2 levels are reduced in enhanced heart inflammation.

Since AIM2 is an IFN-inducible protein (Choubey et al., 2010), we tested AIM2 expression in different cell lines after stimulation with either IFN- $\gamma$, LPS, or IFN- $\gamma$ and LPS combined. We found that stimulation with IFN- $\gamma$ alone induced the expression of AIM2 in HL-1 cardiomyocytes and RAW monocytes, but not in $\mathrm{H} 9 \mathrm{C} 2$ cardiac myoblasts or 3T3 embryonic fibroblasts (Fig. 1A). In contrast, stimulation with LPS alone or IFN- $\gamma$ and LPS combined, down-regulated AIM2 in HL-1 and H9C2 cardiac cells (Fig. 1A), suggesting that AIM2 expression is reduced in cardiac cells upon enhanced inflammation. To determine whether differences in AIM2 protein levels were caused by protein degradation or by transcriptional variations, we first tested HL-1 cardiomyocytes treated with the proteosomal inhibitor MG132. We observed only minor differences in AIM2 protein levels between MG132 treatment and DMSO (vehicle) control (Fig. 1B). On the contrary, we found relevant variations in Aim2 transcription at the RNA level, which reflected 
AIM2 protein levels after IFN- $\gamma$, LPS, or IFN- $\gamma$ + LPS stimulation (Fig. 1C, D, and E). These data suggest that changes in AIM2 protein levels correspond to different Aim2 transcription rather than to AIM2 protein turnover. In addition, since Il-6, Ip-10, and Tnf- $\alpha$ transcription in HL-1 cardiomyocytes was increased only upon combined stimulation with IFN- $\gamma$ and LPS, but not after stimulation with IFN- $\gamma$ or LPS alone (Fig. 1C, D, and E), we suggest that reduced AIM2 expression causes enhanced inflammation in cardiomyocytes.

3.2. AIM2 limits inflammatory cytokine transcription in HL-1 and primary cardiomyocytes, but not in primary cardiac fibroblasts

To figure out whether AIM2-dependent down-regulation of inflammatory cytokines is a unique feature of cardiac cells, we knocked down AIM2 in HL-1 cardiomyocytes, primary mouse neonatal cardiomyocytes (MNC), 3T3 embryonic fibroblasts, and primary cardiac fibroblasts (MNF). Upon combined stimulation with IFN- $\gamma$ and LPS, transcription of the pro-inflammatory cytokines Il-6, Ip-10, and Tnf- $\alpha$ was significantly increased in AIM2-knocked-down HL-1 cardiomyocytes and MNC compared to their mock-treated controls, while knock-down of AIM2 rather led to inconsistent or even reduced cytokine transcription in MNF and 3T3 cells (Fig. 2A, B, and C; Suppl. Fig. S2). These results indicate that AIM2 specifically limits inflammatory cytokine transcription in cardiomyocytes.

Since AIM2 is a component of the inflammasome (Fernandes-Alnemri et al., 2009), we checked whether other members of the inflammasome family might also affect pro-inflammatory cytokine transcription in cardiomyocytes. In contrast to AIM2 depletion, knocking-down of NLRP3 or NLRC4 did not affect transcription of Il-6 and Tnf- $\alpha$, while Ip-10 transcription was increased but less than in AIM2-depleted HL-1 cardiomyocytes (Fig. 2A). To further sustain our results, we compared loss-of-function experiments by knocking down AIM2 with siRNA, with 
gain-of function experiments by over-expressing AIM2 with a vector. Pro-inflammatory cytokine transcription in stimulated HL-1 cardiomyocytes was increased after AIM2 depletion and inhibited after AIM2 over-expression (Fig. 2D and E). Together, these results further indicate that AIM2 limits inflammatory responses in cardiomyocytes.

\subsection{The anti-inflammatory potential of AIM2 in cardiomyocytes is independent of Caspase-1}

Caspase-1 and cell death are enhanced in HL-1 cardiomyocytes after stimulation with nigericin, a factor that specifically activates Caspase-1-dependent inflammasome (Choubey et al., 2010; Mezzaroma et al., 2011). In addition, the inflammasome can be activated by LPS stimulation in neonatal cardiac fibroblasts, but not in neonatal cardiomyocytes (Cresswell et al., 2005; Kawaguchi et al., 2011; Sandanger et al., 2013). Investigating the role of Caspase-1 in HL-1 cardiomyocytes upon combined stimulation with IFN- $\gamma$ and LPS, we found that knocking-down of Caspase-1 had no effect on pro-inflammatory cytokine transcription (Fig. 3A). In addition, double knockdown of AIM2 and Caspase-1 showed the same pro-inflammatory cytokine transcription profile as in AIM2 knocked-down HL-1 cells, suggesting that Caspase-1 is not necessary for the regulatory function of AIM2.

Since Caspase-1 did not seem to functionally contribute to inflammatory cytokine regulation in HL-1 cardiomyocytes, it was not surprising that there was only minimal Caspase- 1 cleavage in cardiac cells, while prominent Caspase-1 cleavage was detectable in 3T3 fibroblasts upon stimulation (Fig. 3B). These results indicate that AIM2 suppresses pro-inflammatory cytokines in cardiomyocytes in a Caspase-1/inflammasome-independent manner.

\subsection{AIM2 down-regulates $N F-\kappa B$ p65 phosphorylation and acetylation}


$\mathrm{NF}-\kappa \mathrm{B}$ p65 is one of the main transcription factors involved in pro-inflammatory cytokine gene transcription (Takeuchi and Akira, 2010). To figure out if the inhibitory effect of AIM2 on inflammatory gene transcription was correlated with increased post-translational modifications of the transcription factor NF- $\kappa \mathrm{B}$, we analyzed siMOCK- and siAIM2-transfected HL-1 cells before and after combined stimulation with IFN- $\gamma$ and LPS. Interestingly, we observed increased IкB$\alpha$ degradation in AIM2-deficient cells (Fig. 4A), which may indicate an increased activation of $\mathrm{NF}-\kappa \mathrm{B}$ and consequent enhancement of inflammatory gene transcription (Ruland, 2011). Since NF- $\mathrm{B}$ p65 phosphorylation and acetylation determines the extent of inflammatory cytokine tran-

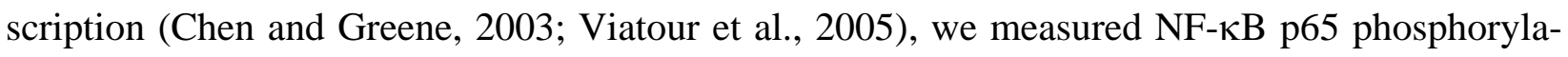
tion and acetylation. NF- $\mathrm{B}$ p65 phosphorylation and acetylation were markedly increased after knocking-down AIM2 (Fig. 4A), suggesting that AIM2 limits inflammatory gene transcription by

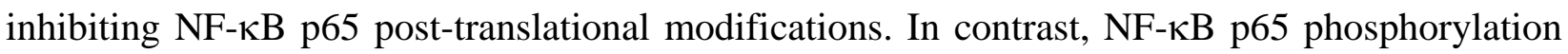
in MNF was comparable in the presence or absence of AIM2 (Fig. 4B), consistent with the equivalent or slightly decreased levels of inflammatory cytokine transcription in the absence of AIM2 shown in Fig. 3C. These data suggest that AIM2 specifically protects cardiomyocytes from excessive inflammatory responses.

\subsection{AIM2 is localized in the cytoplasm}

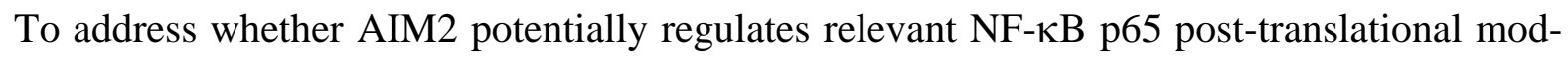
ifications in the nucleus, we analyzed cytoplasmic and nuclear extracts by western blot, as well as fixed cells by immunofluorescence. We found that AIM2 was exclusively located in the cytoplasm of HL-1 cardiomyocytes (Fig. 4C) and AIM2-overexpressing HEK293 cells (Fig. 4D). To exclude that AIM2 was only transiently expressed in the nucleus, we used leptomycin B (LMB), an inhibitor of nuclear export. As a positive control we used NF- $\kappa \mathrm{B}$ p65, which is known to 
translocate into the nucleus and then quickly re-released into the cytoplasm (Vallabhapurapu and Karin, 2009). Indeed, NF-кB p65 was detectable in the nucleus after treating HL-1 cells with LMB (Suppl. Fig. S3A and B), while AIM2, on the contrary, was never detectable in the nucleus, but only in the cytoplasm (Fig. 4E). Taken together, these data suggest that AIM2 inhibits NF- $\kappa \mathrm{B}$ p65 phosphorylation and acetylation indirectly, possibly by regulating other factors in the cytoplasm that translocate into the nucleus and affect NF- $\kappa \mathrm{B}$ p65 activation.

3.6. AIM2 limits NF-кB p65-dependent inflammatory cytokines indirectly by inhibiting STAT1 phosphorylation

The IFN- $\gamma$ signaling pathway converges at STAT1, which undergoes phosphorylation and homo-dimerization before translocating to the nucleus (Hu and Ivashkiv, 2009). Besides promoting the transcription of genes containing the IFN- $\gamma$-activated sequences (GAS), STAT1 facilitates and prolongs the recruitment of NF- $\mathrm{NB}$ p65 to the promoters and enhancers of genes that transcribe inflammatory cytokines (Hu and Ivashkiv, 2009; Qiao et al., 2013). Therefore, STAT1 can be a potential candidate to be under direct control of AIM2 in cardiomyocytes. To test this hypothesis, we first elucidated whether AIM2 interacts with STAT1. After co-transfecting HEK293 cells with EGFP-tagged AIM2-encoding vector together with FLAG-tagged STAT1-, STAT4-, STAT $5 \alpha$ - or STAT5 $\beta$-encoding vector, FLAG-tagged proteins were pulled down. Among the different STATs proteins tested, AIM2 co-immunoprecipitated only with STAT1 (Fig. 5A). These results suggest a direct interaction between AIM2 and STAT1.

We therefore analyzed STAT1 in AIM2- and MOCK-knocked-down HL-1 cardiomyocytes before and after stimulation. AIM2 knock down resulted in extended STAT1 phosphorylation compared to HL-1 control cells (Fig. 5B). In leukocytes, the JAK/STAT pathway, besides phosphorylating STAT1 upon activation of the IFN- $\gamma$ receptor, also involves the phosphorylation of 
JAK1 and JAK2 (Hu et al., 2002; Levy and Darnell, 2002). Hence, we investigated JAK2 phosphorylation after stimulation, but did not detect any phosphorylated JAK2 in HL-1 cells (Suppl. Fig. S4A and B). The non-participation of JAK2 in the inflammatory signaling pathway of cardiomyocytes was also demonstrated in RAW monocytes and HL-1 cardiomyocytes by inhibiting JAK2 activity with Fedratinib (TG101438), a specific JAK2 inhibitor. Indeed, stimulated RAW cells treated with the JAK2 inhibitor showed reduced STAT1 phosphorylation when compared to sham-treated RAW cells, while phosphorylated STAT1 was unaffected or even slightly increased by titrating concentrations of Fedratinib in stimulated HL-1 cells (Suppl. Fig. S4C). These data suggest that STAT1 phosphorylation in HL-1 cells is JAK-independent.

The dependency of AIM2 on STAT1 was confirmed after inducing double knockdown of AIM2 and STAT1 in HL-1 cells. Indeed, Ip-10, an IFN- $\gamma$-induced protein under the control of STAT1 and NF-кB p65 (Begitt et al., 2014), was highly expressed after depletion of AIM2, as already shown in Figures 2A and 3A, but after double knockdown of AIM2 and STAT1, Ip-10 levels were even lower than in siMOCK-treated HL-1 cardiomyocytes (Fig. 5D). Consistently, the

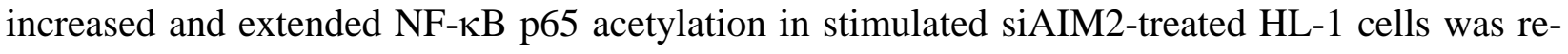
duced in STAT1 knocked-down and AIM2/STAT1 double knocked-down HL-1 cells 2 hours after stimulation (Fig. 5E). These results show that in the absence of STAT1, the inhibitory effect of AIM2 is dampened, suggesting that AIM2 specifically targets STAT1 to limit pro-inflammatory cytokine transcription.

The biological relevance of AIM2 in cardiomyocytes was further studied by evaluating the expression of brain natriuretic peptide (BNP). BNP, a well-established biomarker for heart failure diagnosis, is released by cardiomyocytes under stress conditions during heart failure to reduce cardiac hypertrophy and fibrosis (Doust et al., 2005). Increased BNP concentrations correlate with higher mortality (Dargie, 2005). We analyzed BNP transcription in AIM2 single and 


\begin{abstract}
AIM2/STAT1 double knocked-down HL-1 cardiomyocytes before and after stimulation. The increase in BNP transcription after AIM2 depletion compared to their MOCK-treated control HL-1 cardiomyocytes indicated that AIM2 reduced cardiomyocyte stress (Fig. 5F). Overall, our results suggest that AIM2-dependent limitation of pro-inflammatory cytokine transcription is beneficial to cardiomyocytes.
\end{abstract}




\section{Discussion}

In this study, we provide evidence for a regulatory role of AIM2 in inflammation. We found that AIM2 limited the sensitivity of cardiomyocytes to express the pro-inflammatory cytokines IL-6, IP-10, and TNF- $\alpha$ in response to the inflammatory stimuli IFN- $\gamma$ and LPS. Mechanistically, AIM2 down-regulated NF-kB p65-dependent transcription of pro-inflammatory genes by blocking STAT1 phosphorylation.

Heart inflammation is induced after the release of damaging factors from the stressed heart or from heart-infiltrating inflammatory cells of bone marrow or splenic origin (Mann, 2011). Among them, IFN- $\gamma$ is highly expressed in acute heart inflammation by natural killer cells and macrophages and by type $1 \mathrm{~T}$ helper cells in autoimmune heart disease (Han et al., 2012; Valaperti et al., 2013; White et al., 2014). The effects of IFN- $\gamma$ on cardiac cells are largely underestimated. It is known that activation of TLR4 by heat-shock proteins or LPS worsens the outcome of myocardial infarction and myocarditis (Frisancho-Kiss et al., 2007; Jenke et al., 2013). In addition, some specific molecules dampen the effect of IFN- $\gamma$-triggered inflammation by targeting STAT1. For instance, specific suppressors of cytokine signaling (SOCS) mount an inhibitory response against STAT1 in cardiomyocytes (O'Shea and Murray, 2008), but SOCS1 was also shown to promote the progression from heart hypertrophy to heart failure in an experimental rat model (Cittadini et al., 2012). Therefore, it was necessary to find molecules which limit the inflammatory molecular signaling pathway triggered by IFN- $\gamma$ in the heart. We focused on AIM2 as a possible candidate, because it was expressed in heart tissue, and its reduced transcription correlated with markedly increased inflammatory responses in the heart after CVB3 infection and myocardial infarction. Furthermore, its reduction in IFN- $\gamma / \mathrm{LPS}$-stimulated cardiac cells correlated with increased pro-inflammatory cytokine transcription. 
AIM2 has been mostly studied as a component of the inflammasome, which triggers Caspase-1-dependent cell death (pyroptosis) and activation of the inflammatory cytokines IL-1 $\beta$ and IL-18 (Fernandes-Alnemri et al., 2009). Although it is not yet clear whether inflammasome/Caspase-1-independent pathways contribute to or protect from heart injury, some of these pathways have been described, showing opposite outcomes. Indeed, after I/R injury, NLRP3 contributes to worsen the disease in an inflammasome-independent manner (Takahashi, 2014), while in the autoimmune disease lupus erythematous, AIM2 promotes healing in an inflammasomeindependent fashion (Panchanathan et al., 2011; Panchanathan et al., 2010). Two recent studies describe how AIM2 limits colorectal cancer development in mice in an inflammasome- and IL1 $\beta$-independent manner (Man et al., 2015; Wilson et al., 2015). AIM2 was able to suppress cellular proliferation of intestinal cells and limited the activation of Akt, a master regulator of cell proliferation, showing that AIM2 reduced disease susceptibility in non-bone marrow cells, such as cancer cells and epithelial cells (Man et al., 2015; Wilson et al., 2015). In the present study, we describe for the first time a protective inflammasome-independent function of AIM2 in cardiomyocyte inflammation. Interestingly, comparing the potential anti-inflammatory function of other components of the inflammasome, such as NLRP3 or NLRC4, only AIM2 limited proinflammatory responses in cardiomyocytes. Our data indicate that inflammasome components may have unique intrinsic roles in different cell types, such as cardiomyocytes and leukocytes.

The pro-inflammatory cytokines IL-6 and TNF- $\alpha$ have been widely described as detrimental factors in myocardial infarction and autoimmune myocarditis when their expression is prolonged (Valaperti, 2016). Both cytokines, along with the chemokine IP-10, act as mobilization signals for inflammatory cells to the damaged area in the heart (Kobara et al., 2010; Sun et al., 2007). Depletion of IL-6 with serial injections of anti-IL-6 antibodies shows relevant improvements in mice with myocardial infarction (Kobara et al., 2010). IL-6 is essential to differentiate heart- 
specific auto-aggressive T helper 17 cells (Th17) in autoimmune myocarditis (Eriksson et al., 2003). Similarly, TNF- $\alpha$ has been shown to promote cardiomyocyte apoptosis in myocardial infarction (Kubota et al., 1997; Sun et al., 2007), while its role in myocarditis has not yet been elucidated. In the present study, we show that IL-6, IP-10, and TNF- $\alpha$ were down-regulated by AIM2 in cardiomyocytes in a cell culture setting with combination of IFN- $\gamma$ and LPS stimuli that mimicked the unfavorable heart milieu observed during inflammation.

Transcription of inflammatory cytokines is regulated by NF- $\kappa \mathrm{B}$ p65, which translocates to the nucleus after TLR activation (Takeuchi and Akira, 2010). NF- $\mathrm{B}$ p65 phosphorylation at serine 536 and acetylation at lysine 310 are required for its full transcriptional activity (Chen et al., 2002), which is necessary to promote pro-inflammatory cytokine gene transcription (Rothgiesser et al., 2010). Here we found that AIM2 enhanced NF- $\mathrm{B}$ p 65 phosphorylation and acetylation in stimulated cardiomyocytes. Since AIM2 was localized only in the cytoplasm of cardiac cells, we proposed that AIM2 influences NF- $\mathrm{B}$ p65 phosphorylation and acetylation indirectly, by regulating molecules in the cytoplasm, which have the potential to modulate posttranslational modifi-

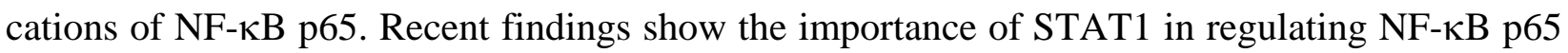
inflammatory gene transcription after priming macrophages with IFN- $\gamma$ (Qiao et al., 2013). In the present study, we found that AIM2 molecularly interacted with STAT1 and limited STAT1 phosphorylation in HL-1 cardiomyocytes, suggesting a direct AIM2-dependent reduction of STAT1 activation. Furthermore, we found that simultaneous knockdown of AIM2 and STAT1 abrogated the beneficial effect of AIM2. Our results support the idea that AIM2 down-regulates proinflammatory cytokine transcription by directly limiting STAT1 activity, which in turn reduces $\mathrm{NF}-\kappa \mathrm{B}$ p65 phosphorylation and acetylation in cardiomyocytes. It is known that NF- $\kappa \mathrm{B}$ p65 acetylation at lysine 310 is controlled by the co-factor p300 (Buerki et al., 2008), while its deacetylation is controlled by SIRT1 and histone deacetylase (HDAC)3 (Ziesche et al., 2013). Intriguingly, 
STAT1 is a recruiter of HATs (Qiao et al., 2013), while it is not know how STAT1 regulates p300-induced NF-кB p65 acetylation. Therefore, future studies are necessary to elucidate how AIM2 regulates STAT1 phosphorylation and how STAT1 affects NF- $\kappa$ B p65 acetylation. In addition, it is not yet clear if AIM2-dependent STAT1 inhibition blocks IFN- $\gamma$ production. We showed that siMOCK and siSTAT1-transfected HL-1 cardiomyocytes expressed comparable levels of AIM2. This would suggest that lack of STAT1, which also regulates IFN- $\gamma$ expression, does not affect a possible autocrine activation of AIM2 by IFN- $\gamma$ produced in HL-1 cardiomyocytes. Although IFN- $\gamma$ transcription is mainly regulated by the transcription factors CREB, ATF2, and c-Jun (Samten et al., 2008), further studies are necessary to figure out if AIM2 affects factors responsible for IFN- $\gamma$ transcription.

In several immune cells of lymphoid and myeloid origin, such as natural killer cells, helper and effector T cells, macrophages, and dendritic cells, the signaling downstream of IFN- $\gamma$ receptor usually leads to tyrosine phosphorylation of JAK1 and JAK2, which in turn promote serine and tyrosine phosphorylation of STAT1 and its homo-dimerization (Levy and Darnell, 2002; Marodi and Notarangelo, 2007). In the present study we showed that neither JAK1 nor JAK2 were phosphorylated in HL-1 cardiomyocytes upon stimulation with IFN- $\gamma$ and LPS. However, we found that the total protein levels of JAK2 were highly reduced in control HL-1 cells when compared to AIM2-deficient HL-1 cells after stimulation, suggesting that in cardiomyocytes, JAK2 may have a scaffold function that is functionally more relevant than its phosphorylation. To corroborate our findings, a recent study demonstrates a novel scaffold function of JAK2 by comparing mouse embryonic fibroblasts (MEFs) extracted from JAK2 kinase-deficient mice and MEFs extracted from JAK2-knockout mice (Keil et al., 2014). Interestingly, upon IFN- $\gamma$ stimulation, JAK2 kinase-deficient MEFs, but not JAK2 knockout MEFs, are still able to induce STAT1 
phosphorylation (Keil et al., 2014), suggesting a scaffold function of JAK2 that supports STAT1 phosphorylation.

Growing evidence over the last years suggests that cardiac cells are responsible for regulating the composition of heart-infiltrating cells during inflammation (Frangogiannis, 2012; White et al., 2014). By responding to inflammatory stimuli, heart-infiltrating cells produce cytokines and chemokines, which in turn amplify the inflammatory milieu in the heart (Wu et al., 2014). It seems that cardiac fibroblasts, rather than cardiomyocytes, react to inflammatory factors (Wu et al., 2014). Therefore, we sought to understand why cardiomyocytes only minimally react to IFN$\gamma$ and TLR4 ligands, which are two factors highly expressed in the heart during inflammation (Mann, 2011). Hence, we knocked-down AIM2 in cardiomyocytes and found that the low sensitivity of cardiomyocytes to inflammatory factors was kept by AIM2. In fact, AIM2 protected cardiomyocytes from excessive inflammatory cytokine transcription and reduced the production of BNP, a biomarker that reflects cardiomyocyte stress. However, further studies are necessary to elucidate whether the interaction between cardiomyocytes, cardiac fibroblasts, and endothelial cells, can modulate the balance of inflammatory responses in the heart during myocardial infarction or myocarditis in an AIM2-dependent manner. The clinical relevance of AIM2 has been shown in patients with colorectal cancer. It has been observed that patients lacking AIM2 expression in their tumor cells developed higher disease recurrence when compared to patients with intact AIM2 expression, suggesting the potential use of AIM2 as a prognostic biomarker for colorectal cancer (Dihlmann et al., 2014). Developing new strategies to enhance the expression of AIM2 in the early phase of MI or during autoimmune myocarditis may be useful to reduce disease severity. Another interesting aspect related to patients with colorectal cancer is the correlation between low AIM2 levels and reduced expression the MHC class II genes HLA-DRA and HLA-DRB, and the class II trans-activator (CIITA) (Lee et al., 2012). Thereby, in the future we 
may be able to understand the different susceptibility among individuals that develop heart diseases.

Taken together, we demonstrate for the first time a novel function for AIM2 as antiinflammatory molecule in cardiomyocytes. Our data show that AIM2 interacts with STAT1 and blocks STAT1-enhanced pro-inflammatory responses. Modulating AIM2 production may be a potential therapeutic strategy to minimize cardiac inflammation and reduce the risk of chronic heart failure. 


\section{Disclosures}

The authors have no financial conflicts of interest.

\section{Acknowledgments}

We thank Dr. Teresa Fernandes-Alnemri for providing us with the anti-AIM2 antibody. We also thank Dr. Liyong Zhang and Dr. Peter Liu for infarcted hearts. We are grateful to Dr. Stephan Christen for helpful advice.

This work was supported by the Mäxi Stiftung. Dr. Alan Valaperti got support from the Forschungskredit of the University of Zurich and the Swiss Life Foundation. Dr. Michael O. Hottiger acknowledges support form the Swiss National Foundation (SNF). 


\section{References}

Aoyagi T. and Matsui T., 2011. The Cardiomyocyte as a Source of Cytokines in Cardiac Injury. J. Cell Sci. Ther. 2012.

Begitt A., Droescher M., Meyer T., Schmid C. D., Baker M., Antunes F., Knobeloch K. P., Owen M. R., Naumann R., Decker T. and Vinkemeier U., 2014. STAT1-cooperative DNA binding distinguishes type 1 from type 2 interferon signaling. Nat. Immunol. 15, 168-76.

Boyd J. H., Mathur S., Wang Y., Bateman R. M. and Walley K. R., 2006. Toll-like receptor stimulation in cardiomyoctes decreases contractility and initiates an NF-kappaB dependent inflammatory response. Cardiovasc. Res. 72, 384-93.

Brown M. A. and Jones W. K., 2004. NF-kappaB action in sepsis: the innate immune system and the heart. Front. Biosci. 9, 1201-17.

Buerki C., Rothgiesser K. M., Valovka T., Owen H. R., Rehrauer H., Fey M., Lane W. S. and Hottiger M. O., 2008. Functional relevance of novel p300-mediated lysine 314 and 315 acetylation of RelA/p65. Nucleic Acids Res. 36, 1665-80.

Burckstummer T., Baumann C., Bluml S., Dixit E., Durnberger G., Jahn H., Planyavsky M., Bilban M., Colinge J., Bennett K. L. and Superti-Furga G., 2009. An orthogonal proteomic-genomic screen identifies AIM2 as a cytoplasmic DNA sensor for the inflammasome. Nat. Immunol. 10, 266-72.

Chen L. F. and Greene W. C., 2003. Regulation of distinct biological activities of the NF-kappaB transcription factor complex by acetylation. J. Mol. Med. (Berl.) 81, 549-57.

Chen L. F., Mu Y. and Greene W. C., 2002. Acetylation of RelA at discrete sites regulates distinct nuclear functions of NF-kappaB. EMBO J. 21, 6539-48.

Chen L. F., Williams S. A., Mu Y., Nakano H., Duerr J. M., Buckbinder L. and Greene W. C., 2005. NF-kappaB RelA phosphorylation regulates RelA acetylation. Mol. Cell. Biol. 25, 7966-75.

Cheng X., Ding Y., Xia C., Tang T., Yu X., Xie J., Liao M., Yao R., Chen Y., Wang M. and Liao Y. H., 2009. Atorvastatin modulates Th1/Th2 response in patients with chronic heart failure. J. Card. Fail. 15, 158-62.

Cheng X., Liao Y. H., Ge H., Li B., Zhang J., Yuan J., Wang M., Liu Y., Guo Z., Chen J., Zhang J. and Zhang L., 2005a. TH1/TH2 functional imbalance after acute myocardial infarction: coronary arterial inflammation or myocardial inflammation. J. Clin. Immunol. 25, 246-53.

Cheng X., Liao Y. H., Zhang J., Li B., Ge H., Yuan J., Wang M., Lu B., Liu Y. and Cheng Y., 2005b. Effects of Atorvastatin on Th polarization in patients with acute myocardial infarction. Eur. J. Heart Fail. 7, 1099-104.

Choubey D., Duan X., Dickerson E., Ponomareva L., Panchanathan R., Shen H. and Srivastava R., 2010. Interferon-inducible p200-family proteins as novel sensors of cytoplasmic DNA: role in inflammation and autoimmunity. J. Interferon Cytokine Res. 30, 371-80.

Cittadini A., Monti M. G., Iaccarino G., Castiello M. C., Baldi A., Bossone E., Longobardi S., Marra A. M., Petrillo V., Saldamarco L., During M. J., Sacca L. and Condorelli G., 2012. SOCS1 gene transfer accelerates the transition to heart failure through the inhibition of the gp130/JAK/STAT pathway. Cardiovasc. Res. 96, 381-90.

Cresswell K. S., Clarke C. J., Jackson J. T., Darcy P. K., Trapani J. A. and Johnstone R. W., 2005. Biochemical and growth regulatory activities of the HIN-200 family member and putative tumor suppressor protein, AIM2. Biochem. Biophys. Res. Commun. 326, 417-24.

Dargie H., 2005. Heart failure post-myocardial infarction: a review of the issues. Heart 91 Suppl 2, ii3-6; discussion ii31, ii43-8. 
Dihlmann S., Tao S., Echterdiek F., Herpel E., Jansen L., Chang-Claude J., Brenner H., Hoffmeister M. and Kloor M., 2014. Lack of Absent in Melanoma 2 (AIM2) expression in tumor cells is closely associated with poor survival in colorectal cancer patients. Int. J. Cancer 135, 2387-96.

Doust J. A., Pietrzak E., Dobson A. and Glasziou P., 2005. How well does B-type natriuretic peptide predict death and cardiac events in patients with heart failure: systematic review. BMJ 330, 625.

Eriksson U., Kurrer M. O., Schmitz N., Marsch S. C., Fontana A., Eugster H. P. and Kopf M., 2003. Interleukin-6-deficient mice resist development of autoimmune myocarditis associated with impaired upregulation of complement C3. Circulation 107, 320-5.

Fairweather D., Frisancho-Kiss S., Yusung S. A., Barrett M. A., Davis S. E., Gatewood S. J., Njoku D. B. and Rose N. R., 2004. Interferon-gamma protects against chronic viral myocarditis by reducing mast cell degranulation, fibrosis, and the profibrotic cytokines transforming growth factor-beta 1, interleukin-1 beta, and interleukin-4 in the heart. Am. J. Pathol. 165, 1883-94.

Fernandes-Alnemri T., Yu J. W., Datta P., Wu J. and Alnemri E. S., 2009. AIM2 activates the inflammasome and cell death in response to cytoplasmic DNA. Nature 458, 509-13.

Fernandes-Alnemri T., Yu J. W., Juliana C., Solorzano L., Kang S., Wu J., Datta P., McCormick M., Huang L., McDermott E., Eisenlohr L., Landel C. P. and Alnemri E. S., 2010. The AIM2 inflammasome is critical for innate immunity to Francisella tularensis. Nat. Immunol. 11, 385-93.

Frangogiannis N. G., 2012. Regulation of the inflammatory response in cardiac repair. Circ. Res. $110,159-73$.

Frisancho-Kiss S., Davis S. E., Nyland J. F., Frisancho J. A., Cihakova D., Barrett M. A., Rose N. R. and Fairweather D., 2007. Cutting edge: cross-regulation by TLR4 and T cell Ig mucin-3 determines sex differences in inflammatory heart disease. J. Immunol. 178, 6710-4.

Ghosh S. and Hayden M. S., 2008. New regulators of NF-kappaB in inflammation. Nat. Rev. Immunol. 8, 837-48.

Han Y. L., Li Y. L., Jia L. X., Cheng J. Z., Qi Y. F., Zhang H. J. and Du J., 2012. Reciprocal interaction between macrophages and T cells stimulates IFN-gamma and MCP-1 production in Ang II-induced cardiac inflammation and fibrosis. PLoS One 7, e35506.

Hellkvist J., Tufveson G., Gerdin B. and Johnsson C., 2002. Characterization of fibroblasts from rejecting tissue: the hyaluronan production is increased. Transplantation 74, 1672-7.

Hornung V., Ablasser A., Charrel-Dennis M., Bauernfeind F., Horvath G., Caffrey D. R., Latz E. and Fitzgerald K. A., 2009. AIM2 recognizes cytosolic dsDNA and forms a caspase-1activating inflammasome with ASC. Nature 458, 514-8.

Hu X., Herrero C., Li W. P., Antoniv T. T., Falck-Pedersen E., Koch A. E., Woods J. M., Haines G. K. and Ivashkiv L. B., 2002. Sensitization of IFN-gamma Jak-STAT signaling during macrophage activation. Nat. Immunol. 3, 859-66.

Hu X. and Ivashkiv L. B., 2009. Cross-regulation of signaling pathways by interferon-gamma: implications for immune responses and autoimmune diseases. Immunity 31, 539-50.

Jenke A., Wilk S., Poller W., Eriksson U., Valaperti A., Rauch B. H., Stroux A., Liu P., Schultheiss H. P., Scheibenbogen C. and Skurk C., 2013. Adiponectin protects against Toll-like receptor 4-mediated cardiac inflammation and injury. Cardiovasc. Res. 99, 42231.

Kawaguchi M., Takahashi M., Hata T., Kashima Y., Usui F., Morimoto H., Izawa A., Takahashi Y., Masumoto J., Koyama J., Hongo M., Noda T., Nakayama J., Sagara J., Taniguchi S. 
and Ikeda U., 2011. Inflammasome activation of cardiac fibroblasts is essential for myocardial ischemia/reperfusion injury. Circulation 123, 594-604.

Keil E., Finkenstadt D., Wufka C., Trilling M., Liebfried P., Strobl B., Muller M. and Pfeffer K., 2014. Important scaffold function of the Janus kinase 2 uncovered by a novel mouse model harboring a Jak2 activation-loop mutation. Blood 123, 520-9.

Kobara M., Noda K., Kitamura M., Okamoto A., Shiraishi T., Toba H., Matsubara H. and Nakata T., 2010. Antibody against interleukin-6 receptor attenuates left ventricular remodelling after myocardial infarction in mice. Cardiovasc. Res. 87, 424-30.

Krum H. and Abraham W. T., 2009. Heart failure. Lancet 373, 941-55.

Kubota T., McTiernan C. F., Frye C. S., Demetris A. J. and Feldman A. M., 1997. Cardiacspecific overexpression of tumor necrosis factor-alpha causes lethal myocarditis in transgenic mice. J. Card. Fail. 3, 117-24.

Lee J., Li L., Gretz N., Gebert J. and Dihlmann S., 2012. Absent in Melanoma 2 (AIM2) is an important mediator of interferon-dependent and -independent HLA-DRA and HLA-DRB gene expression in colorectal cancers. Oncogene 31, 1242-53.

Levy D. E. and Darnell J. E., Jr., 2002. Stats: transcriptional control and biological impact. Nat. Rev. Mol. Cell Biol. 3, 651-62.

Lindner D., Li J., Savvatis K., Klingel K., Blankenberg S., Tschope C. and Westermann D., 2014. Cardiac fibroblasts aggravate viral myocarditis: cell specific coxsackievirus B3 replication. Mediators Inflamm. 2014, 519528.

Man S. M., Zhu Q., Zhu L., Liu Z., Karki R., Malik A., Sharma D., Li L., Malireddi R. K., Gurung P., Neale G., Olsen S. R., Carter R. A., McGoldrick D. J., Wu G., Finkelstein D., Vogel P., Gilbertson R. J. and Kanneganti T. D., 2015. Critical Role for the DNA Sensor AIM2 in Stem Cell Proliferation and Cancer. Cell 162, 45-58.

Mann D. L., 2011. The emerging role of innate immunity in the heart and vascular system: for whom the cell tolls. Circ. Res. 108, 1133-45.

Marchetti C., Toldo S., Chojnacki J., Mezzaroma E., Liu K., Salloum F. N., Nordio A., Carbone S., Mauro A. G., Das A., Zalavadia A. A., Halquist M. S., Federici M., Van Tassell B. W., Zhang S. and Abbate A., 2015. Pharmacologic Inhibition of the NLRP3 Inflammasome Preserves Cardiac Function After Ischemic and Nonischemic Injury in the Mouse. J. Cardiovasc. Pharmacol. 66, 1-8.

Marodi L. and Notarangelo L. D., 2007. Immunological and genetic bases of new primary immunodeficiencies. Nat. Rev. Immunol. 7, 851-61.

McCormick J., Suleman N., Scarabelli T. M., Knight R. A., Latchman D. S. and Stephanou A., 2012. STAT1 deficiency in the heart protects against myocardial infarction by enhancing autophagy. J. Cell. Mol. Med. 16, 386-93.

Mezzaroma E., Toldo S., Farkas D., Seropian I. M., Van Tassell B. W., Salloum F. N., Kannan H. R., Menna A. C., Voelkel N. F. and Abbate A., 2011. The inflammasome promotes adverse cardiac remodeling following acute myocardial infarction in the mouse. Proc. Natl. Acad. Sci. U. S. A. 108, 19725-30.

Nwachukwu J. C., Srinivasan S., Bruno N. E., Parent A. A., Hughes T. S., Pollock J. A., Gjyshi O., Cavett V., Nowak J., Garcia-Ordonez R. D., Houtman R., Griffin P. R., Kojetin D. J., Katzenellenbogen J. A., Conkright M. D. and Nettles K. W., 2014. Resveratrol modulates the inflammatory response via an estrogen receptor-signal integration network. eLife 3, e02057.

O'Shea J. J. and Murray P. J., 2008. Cytokine signaling modules in inflammatory responses. Immunity 28, 477-87. 
Panchanathan R., Duan X., Arumugam M., Shen H., Liu H. and Choubey D., 2011. Cell type and gender-dependent differential regulation of the p202 and Aim2 proteins: implications for the regulation of innate immune responses in SLE. Mol. Immunol. 49, 273-80.

Panchanathan R., Duan X., Shen H., Rathinam V. A., Erickson L. D., Fitzgerald K. A. and Choubey D., 2010. Aim2 deficiency stimulates the expression of IFN-inducible Ifi202, a lupus susceptibility murine gene within the Nba2 autoimmune susceptibility locus. J. Immunol. 185, 7385-93.

Qiao Y., Giannopoulou E. G., Chan C. H., Park S. H., Gong S., Chen J., Hu X., Elemento O. and Ivashkiv L. B., 2013. Synergistic activation of inflammatory cytokine genes by interferon-gamma-induced chromatin remodeling and toll-like receptor signaling. Immunity 39, 454-69.

Rangachari M., Mauermann N., Marty R. R., Dirnhofer S., Kurrer M. O., Komnenovic V., Penninger J. M. and Eriksson U., 2006. T-bet negatively regulates autoimmune myocarditis by suppressing local production of interleukin 17. J. Exp. Med. 203, 2009-19.

Reifenberg K., Lehr H. A., Torzewski M., Steige G., Wiese E., Kupper I., Becker C., Ott S., Nusser P., Yamamura K., Rechtsteiner G., Warger T., Pautz A., Kleinert H., Schmidt A., Pieske B., Wenzel P., Munzel T. and Lohler J., 2007. Interferon-gamma induces chronic active myocarditis and cardiomyopathy in transgenic mice. Am. J. Pathol. 171, 463-72.

Rothgiesser K. M., Erener S., Waibel S., Luscher B. and Hottiger M. O., 2010. SIRT2 regulates NF-kappaB dependent gene expression through deacetylation of p65 Lys310. J. Cell Sci. 123, 4251-8.

Ruland J., 2011. Return to homeostasis: downregulation of NF-kappaB responses. Nat. Immunol. $12,709-14$.

Samten B., Townsend J. C., Weis S. E., Bhoumik A., Klucar P., Shams H. and Barnes P. F., 2008. CREB, ATF, and AP-1 transcription factors regulate IFN-gamma secretion by human T cells in response to mycobacterial antigen. J. Immunol. 181, 2056-64.

Sandanger O., Ranheim T., Vinge L. E., Bliksoen M., Alfsnes K., Finsen A. V., Dahl C. P., Askevold E. T., Florholmen G., Christensen G., Fitzgerald K. A., Lien E., Valen G., Espevik T., Aukrust P. and Yndestad A., 2013. The NLRP3 inflammasome is upregulated in cardiac fibroblasts and mediates myocardial ischaemia-reperfusion injury. Cardiovasc. Res. 99, 164-74.

Stephanou A., 2004. Role of STAT-1 and STAT-3 in ischaemia/reperfusion injury. J. Cell. Mol. Med. 8, 519-25.

Sun M., Chen M., Dawood F., Zurawska U., Li J. Y., Parker T., Kassiri Z., Kirshenbaum L. A., Arnold M., Khokha R. and Liu P. P., 2007. Tumor necrosis factor-alpha mediates cardiac remodeling and ventricular dysfunction after pressure overload state. Circulation 115, 1398-407.

Takahashi M., 2014. NLRP3 inflammasome as a novel player in myocardial infarction. Int. Heart J. 55, 101-5.

Takeuchi O. and Akira S., 2010. Pattern recognition receptors and inflammation. Cell 140, 80520.

Townsend P. A., Scarabelli T. M., Pasini E., Gitti G., Menegazzi M., Suzuki H., Knight R. A., Latchman D. S. and Stephanou A., 2004. Epigallocatechin-3-gallate inhibits STAT-1 activation and protects cardiac myocytes from ischemia/reperfusion-induced apoptosis. FASEB J. 18, 1621-3.

Turner N. A., Mughal R. S., Warburton P., O'Regan D. J., Ball S. G. and Porter K. E., 2007. Mechanism of TNFalpha-induced IL-1alpha, IL-1beta and IL-6 expression in human cardiac fibroblasts: effects of statins and thiazolidinediones. Cardiovasc. Res. 76, 81-90. 
Valaperti A., 2016. Drugs Targeting the Canonical NF-kappaB Pathway to Treat Viral and Autoimmune Myocarditis. Curr. Pharm. Des. 22, 440-9.

Valaperti A., Nishii M., Germano D., Liu P. P. and Eriksson U., 2013. Vaccination with Flt3Linduced CD8alpha+ dendritic cells prevents CD4+ T helper cell-mediated experimental autoimmune myocarditis. Vaccine 31, 4802-11.

Valaperti A., Nishii M., Liu Y., Yang H., Naito K., Liu P. P. and Eriksson U., 2014. The adapter protein c-Cbl-associated protein (CAP) protects from acute CVB3-mediated myocarditis through stabilization of type I interferon production and reduced cytotoxicity. Basic Res. Cardiol. 109, 411.

Vallabhapurapu S. and Karin M., 2009. Regulation and function of NF-kappaB transcription factors in the immune system. Annu. Rev. Immunol. 27, 693-733.

Veeranki S., Duan X., Panchanathan R., Liu H. and Choubey D., 2011. IFI16 protein mediates the anti-inflammatory actions of the type-I interferons through suppression of activation of caspase-1 by inflammasomes. PLoS One 6, e27040.

Viatour P., Merville M. P., Bours V. and Chariot A., 2005. Phosphorylation of NF-kappaB and IkappaB proteins: implications in cancer and inflammation. Trends Biochem. Sci. 30, 4352.

White D. A., Su Y., Kanellakis P., Kiriazis H., Morand E. F., Bucala R., Dart A. M., Gao X. M. and Du X. J., 2014. Differential roles of cardiac and leukocyte derived macrophage migration inhibitory factor in inflammatory responses and cardiac remodelling post myocardial infarction. J. Mol. Cell. Cardiol. 69, 32-42.

Wilson J. E., Petrucelli A. S., Chen L., Koblansky A. A., Truax A. D., Oyama Y., Rogers A. B., Brickey W. J., Wang Y., Schneider M., Muhlbauer M., Chou W. C., Barker B. R., Jobin C., Allbritton N. L., Ramsden D. A., Davis B. K. and Ting J. P., 2015. Inflammasomeindependent role of AIM2 in suppressing colon tumorigenesis via DNA-PK and Akt. Nat. Med. 21, 906-13.

Wu L., Ong S., Talor M. V., Barin J. G., Baldeviano G. C., Kass D. A., Bedja D., Zhang H., Sheikh A., Margolick J. B., Iwakura Y., Rose N. R. and Cihakova D., 2014. Cardiac fibroblasts mediate IL-17A-driven inflammatory dilated cardiomyopathy. J. Exp. Med. 211, 1449-64.

Ziesche E., Kettner-Buhrow D., Weber A., Wittwer T., Jurida L., Soelch J., Muller H., Newel D., Kronich P., Schneider H., Dittrich-Breiholz O., Bhaskara S., Hiebert S. W., Hottiger M. O., Li H., Burstein E., Schmitz M. L. and Kracht M., 2013. The coactivator role of histone deacetylase 3 in IL-1-signaling involves deacetylation of p65 NF-kappaB. Nucleic Acids Res. 41, 90-109. 


\section{Figure legends}

FIGURE 1. Only synergistic stimulation with IFN- $\gamma$ and LPS induces pro-inflammatory cytokine transcription in HL-1 cardiomyocytes.

(A) Immunoblot analysis of AIM2 levels in cardiac cell lines (mouse HL-1 and rat H9C2), mouse monocytes (RAW), and mouse fibroblasts (3T3) stimulated with IFN- $\gamma$ alone, LPS alone, or costimulated with IFN- $\gamma$ and LPS for the indicated hours. GAPDH was used as internal control. The ratio between densitometry values of AIM2 and GAPDH relative to 0 hours is shown.

(B) Immunoblot analysis of AIM2 levels in HL-1 cardiomyocytes pre-treated for 5h with MG132 or DMSO control and then stimulated with IFN- $\gamma$ alone, LPS alone, or co-stimulated with IFN- $\gamma$ and LPS for the indicated hours. GAPDH was used as internal control. The ratio between densitometry values of AIM2 and GAPDH relative to 0 hours is shown.

(C, D, E) HL-1 cardiomyocytes were stimulated with IFN- $\gamma$ alone, LPS alone, or synergistically stimulated with IFN- $\gamma$ and LPS for the indicated hours. Transcription of Aim2 and of the proinflammatory cytokines Il-6, Ip-10, and Tnf- $a$ was analyzed by real-time RT-PCR.

Means \pm s.d. Values measured form one out of three independent experiments (A, B) performed in triplicates (C-E) are shown.

FIGURE 2. AIM2 limits pro-inflammatory cytokine transcription in cardiomyocytes but not in cardiac fibroblasts.

(A) Knocking-down of the inflammasome components AIM2, NLRP3, or NLRC4 with siRNA in HL-1 cardiomyocytes stimulated with IFN- $\gamma$ and LPS for the indicated times. Transcription of the pro-inflammatory cytokines $I l-6, I p-10$, and Tnf- $\alpha$ was determined by real-time RT-PCR.

(B) Knocking-down of AIM2 with siRNA in primary mouse neonatal cardiomyocytes (MNC) 
stimulated with IFN- $\gamma$ and LPS for the indicated times. Transcription of the pro-inflammatory cytokines Il-6, Ip-10, and Tnf- $\alpha$ was determined by real-time RT-PCR.

(C) Knocking-down of AIM2 with siRNA in primary mouse neonatal cardiac fibroblasts (MNF) stimulated with IFN- $\gamma$ and LPS for the indicated times. Transcription of the pro-inflammatory cytokines Il-6, Ip-10, and Tnf- $\alpha$ was determined by real-time RT-PCR.

From A to C: means \pm s.d and values measured form one out of three independent experiments performed in duplicates are shown. ${ }^{*} p<0.05, * * * p<0.001$ for siMOCK vs. siAIM2, siMOCK vs. siNLRP3, or siMOCK vs. siNLRC4. ${ }^{\# \# \# ~} p<0.001$ for siAIM2 vs. siNLRP3 or siAIM2 vs. SiNLRC4.

(D, E) Il-6, Ip-10, and Tnf- $\alpha$ transcription in HL-1 cardiomyocytes depleted of AIM2 by siRNA (D) or supplemented with AIM2-expressing vector (E) was analyzed by real-time RT-PCR. HL-1 cardiomyocytes were stimulated with IFN- $\gamma$ and LPS or left unstimulated. Means \pm s.d. Values measured form one out of two independent experiments performed in duplicates are shown. ${ }^{*} p<$ 0.05

FIGURE 3. Down-regulation of pro-inflammatory cytokines by AIM2 in HL-1 cardiomyocytes is Caspase-1 independent.

(A) Knocking-down of AIM2 or Caspase-1 with siRNA in HL-1 cardiomyocytes stimulated with IFN- $\gamma$ and LPS for the indicated hours. Transcription of the pro-inflammatory cytokines $I l-6, I p$ 10, and Tnf- $\alpha$ was determined by real-time RT-PCR. Means \pm s.d. Values measured form one out of three independent experiments performed in duplicates are shown. ${ }^{*} p<0.05$, $* * * p<0.001$ for siMOCK vs. siAIM2, siMOCK vs. siCaspase1, or siMOCK vs. siAIM2/siCaspase1. ${ }^{\# \#} p<0.001$ for siAIM2 vs. siCaspase1 or siAIM2 vs. siAIM2/siCaspase1. ${ }^{\S \S} p<0.01,{ }^{\S \S} p<0.001$ for siAIM2/siCaspase1 vs. siCaspase1. 
(B) Caspase-1 cleavage was determined by immunoblotting in IFN- $\gamma$ - and LPS-stimulated H9C2 cardiomyoblasts and 3T3 fibroblasts for the indicated hours.

One out of three (A-B) independent experiments is shown.

FIGURE 4. AIM2 limits NF- $\mathrm{B}$ p65 phosphorylation and acetylation.

(A) Total cell lysates collected from MOCK- or AIM2-depleted HL-1 cardiomyocytes stimulated with IFN- $\gamma$ and LPS for the indicated times. NF- $\kappa$ B p65 phosphorylation and acetylation were analyzed by immunoblotting with specific antibodies.

(B) Total cell lysates collected from MOCK- or AIM2-depleted primary mouse neonatal cardiac fibroblasts (MNF) stimulated with IFN- $\gamma$ and LPS for the indicated times. NF- $\kappa$ B p65 phosphorylation was analyzed by immunoblotting with specific antibodies.

(C) Immunofluorescence staining of HL-1 cardiomyocytes transfected with AIM2-EGFPencoding vector. Cells were left unstimulated or stimulated with IFN- $\gamma$ and LPS for the indicated times and then stained with first antibodies detecting total NF- $\kappa \mathrm{B}$ p65 followed by anti-rabbit Cy3 secondary antibody. Magnification 320x.

(D) Immunofluorescence staining to determine AIM2 cellular localization in EGFP-tagged AIM2-transfected HEK293 cells before and after stimulation with IFN- $\gamma$ and LPS. Magnification 320x.

(E) HL-1 cardiomyocytes were pre-treated with LMB or left untreated and then stimulated as indicated. Cytosolic and nuclear extracts were immunoblotted with AIM2 antibodies.

One out of two (C-E) or out of three (A-B) independent experiments is shown.

FIGURE 5. AIM2 binds to STAT1 and limits its phosphorylation.

(A) HEK293 cells were co-transfected with FLAG-tagged STAT1, STAT4, STAT5 $\alpha$, or STAT5 $\beta$ 
vector and AIM2-EGFP vector, as indicated. Physical interaction of AIM2 with FLAG-tagged proteins was analyzed by immunoprecipitation and immunoblotting. One out of three independent experiments is shown.

(B) Total cell lysates collected from HL-1 cardiomyocytes were stimulated with IFN- $\gamma$ and LPS. STAT1 phosphorylation at tyrosine 701 was analyzed by immunoblotting with specific antibodies. Densitometry analysis is shown on the right. One out of three independent experiments is shown. (C) Total cell lysates collected from primary mouse neonatal cardiac fibroblasts (MNF) were stimulated with IFN- $\gamma$ and LPS. STAT1 phosphorylation at tyrosine 701 was analyzed by immunoblotting with specific antibodies. Densitometry analysis is shown on the right. One out of two independent experiments is shown.

(D) Knocking-down of AIM2, STAT1, or AIM2 and STAT1 with siRNA in HL-1 cardiomyocytes were stimulated with IFN- $\gamma$ and LPS for the indicated hours. Transcription of Ip-10 was determined by real-time RT-PCR. Means \pm s.d. Values measured form one out of three independent experiments performed in duplicates are shown. $* * * p<0.001$ for siMOCK vs. siAIM2, siMOCK vs. siSTAT1, or siMOCK vs. siAIM2/siSTAT1. ${ }^{\# \#} p<0.001$ for siAIM2 vs. siSTAT1 or siAIM2 vs. siAIM2/siSTAT1.

(E) Total cell lysates collected from MOCK-, AIM2-, STAT1-, or AIM2 and STAT1-depleted HL1 cardiomyocytes were stimulated with IFN- $\gamma$ and LPS for the indicated times. NF-kB p65 acetylation at lysine 310 was analyzed by immunoblotting with specific antibodies. Densitometry analysis is shown below. The efficiency of STAT1 knocking-down in HL-1 cardiomyocytes is also shown. One out of two independent experiments is shown.

(F) Knocking-down of AIM2 or AIM2 and STAT1 with siRNA in HL-1 cardiomyocytes stimulated with IFN- $\gamma$ and LPS for 24 hours. Transcription of $B N P$ was determined by real-time RT- 
PCR. Means \pm s.d. Values measured form one out of two independent experiments performed in triplicates are shown. ${ }^{* *} p<0.01$ for siAIM2 vs. siMOCK or siAIM2 vs. siAIM2/siSTAT1. 
Figure 1

A

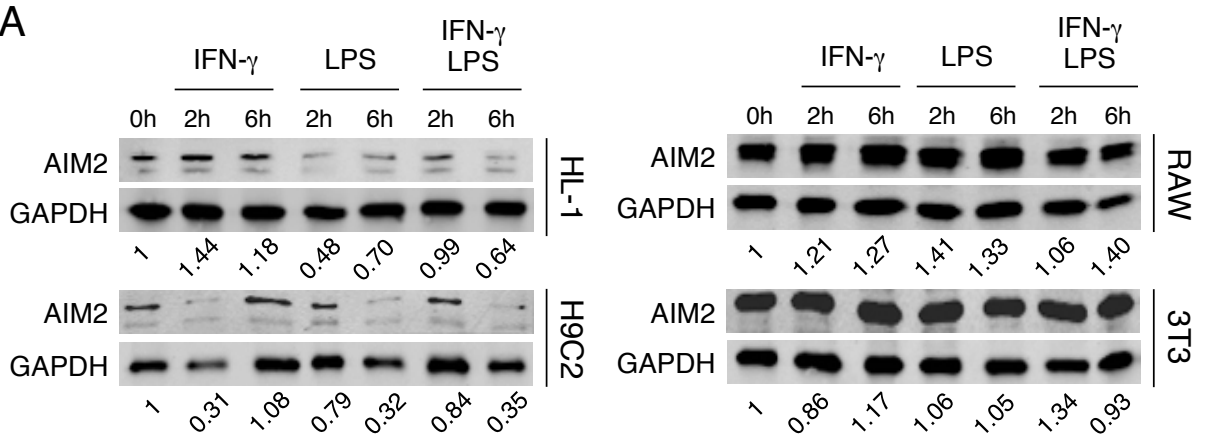

B

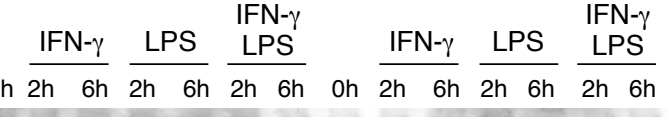

AIM2 - - - - - - - - - - -

GAPDH

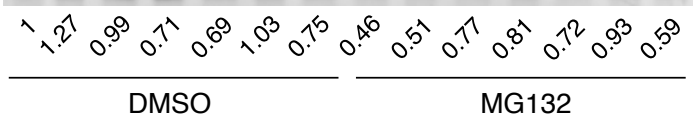
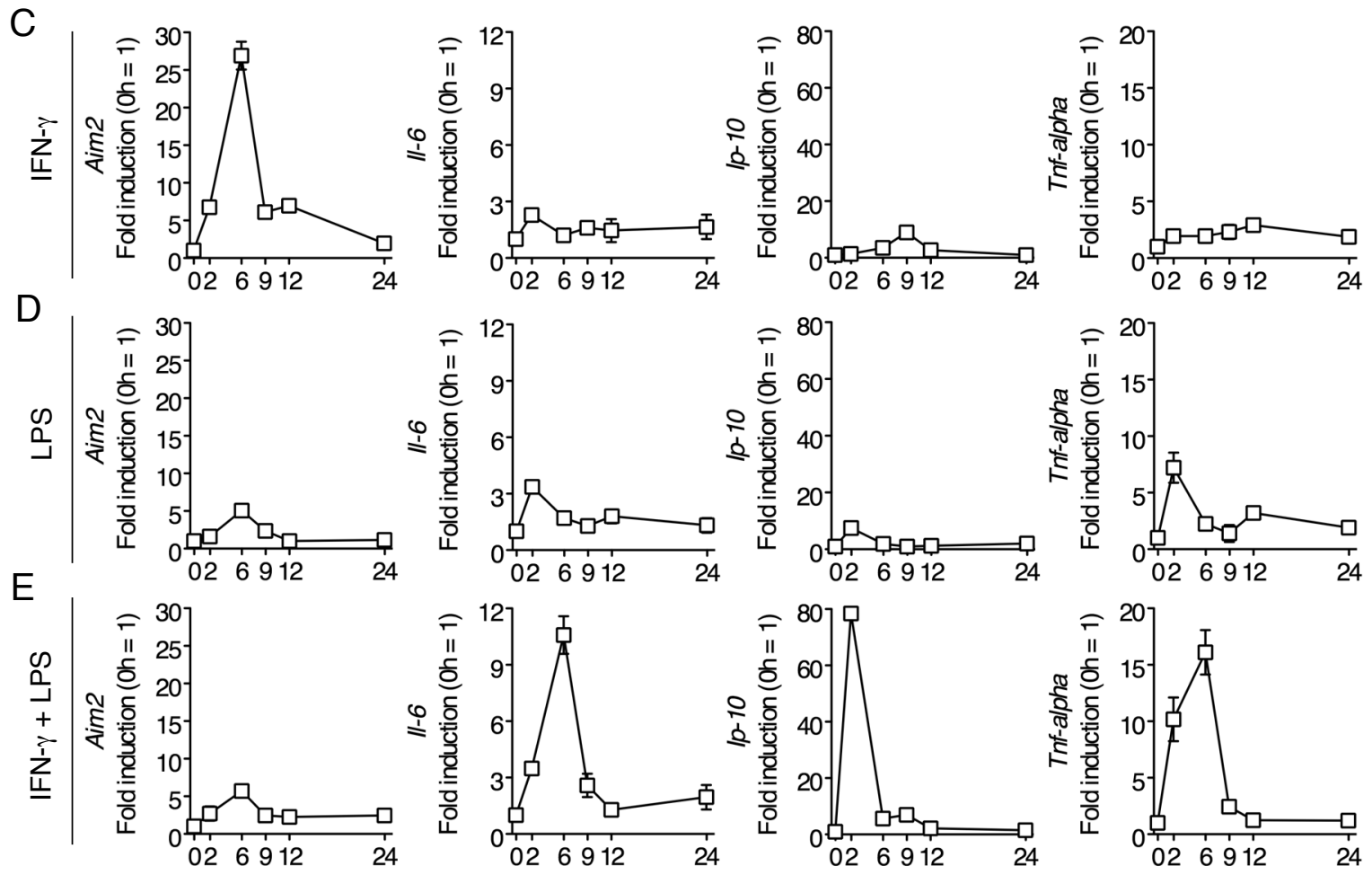
Figure 2

A

B
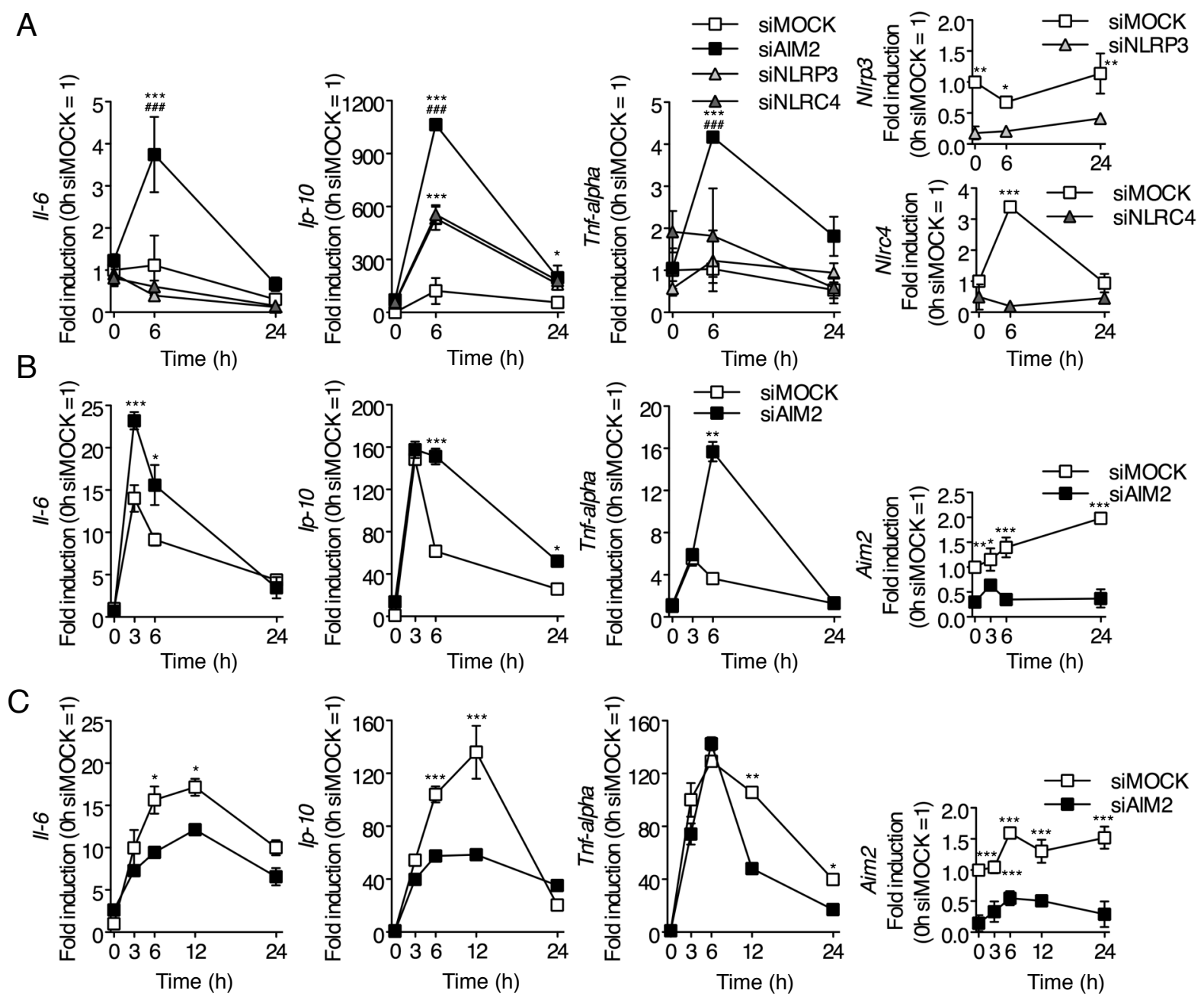

D
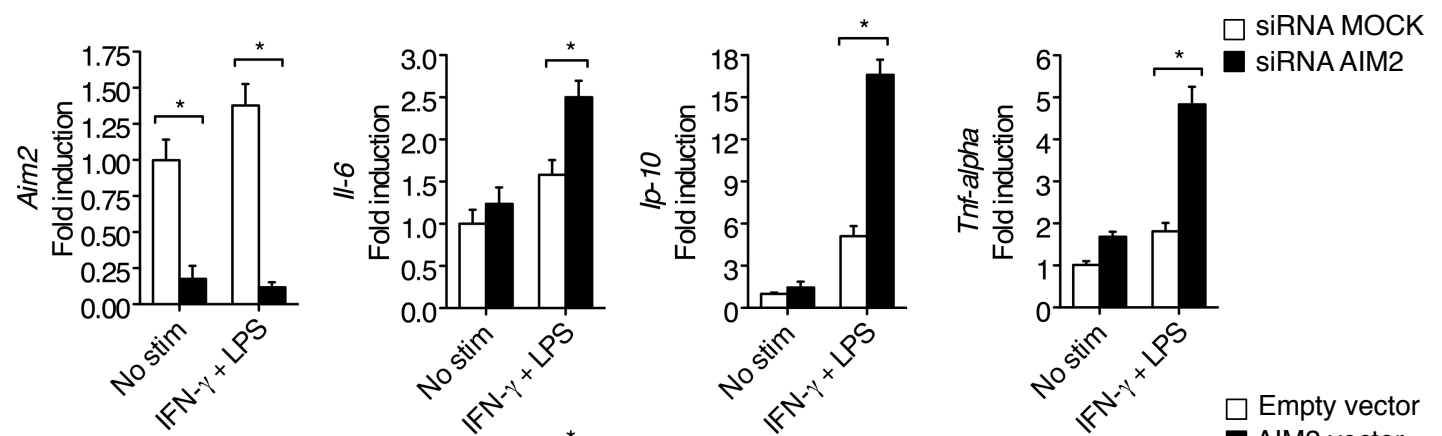

E
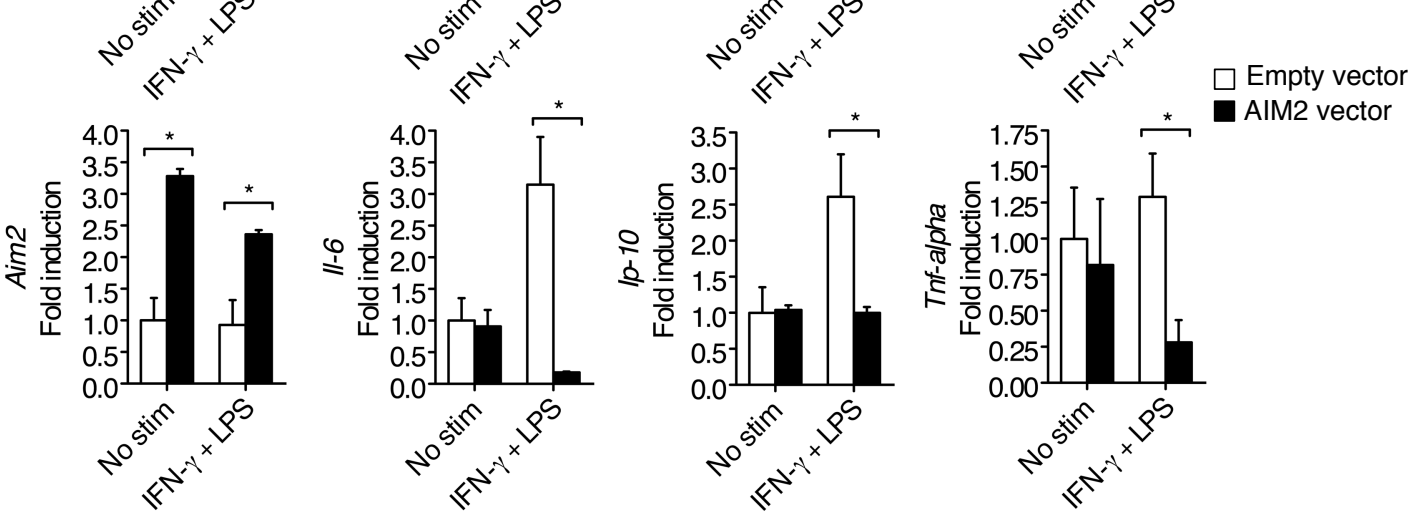
Figure 3

A
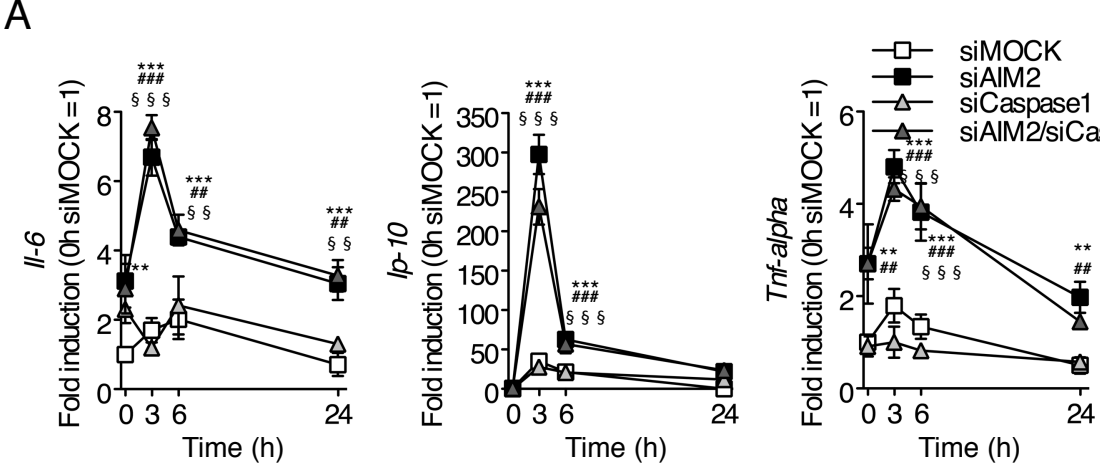

B

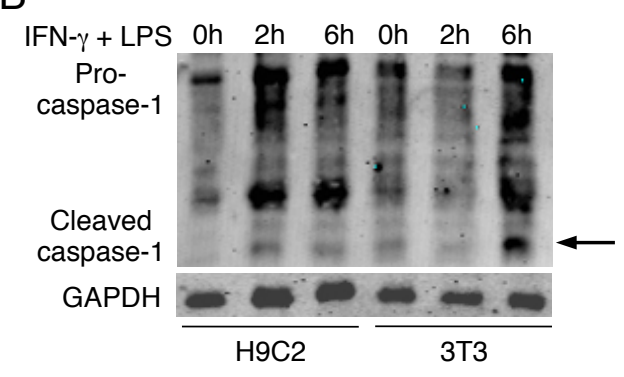


Figure 4

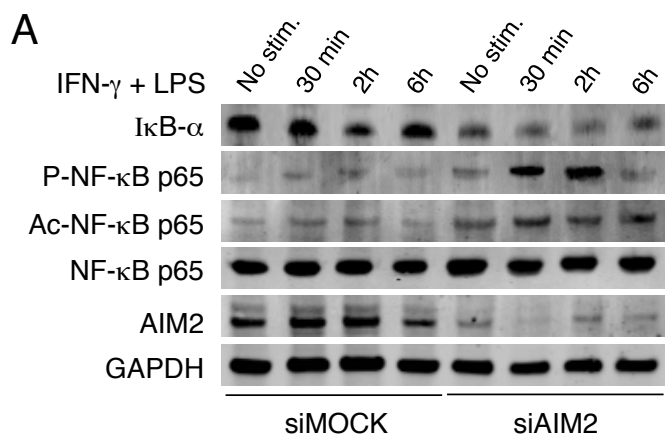

B

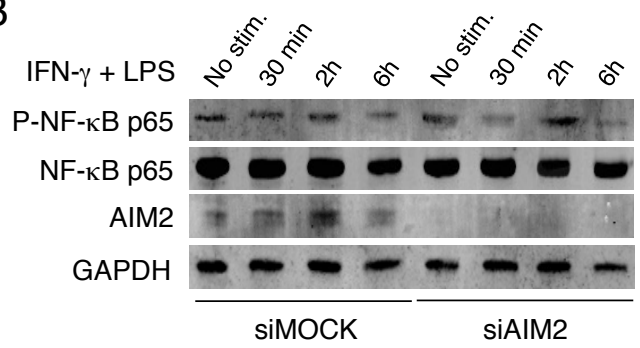

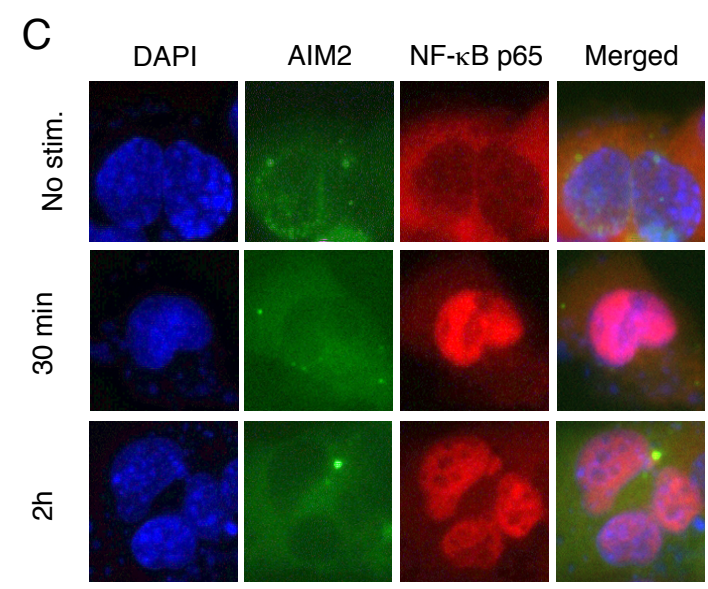

D

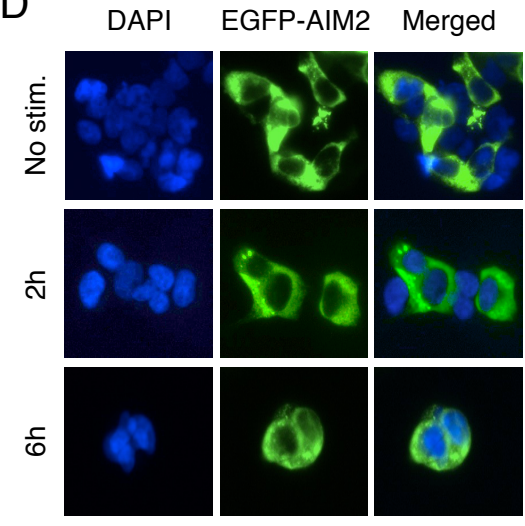

E

Cytosol s Nucleus,

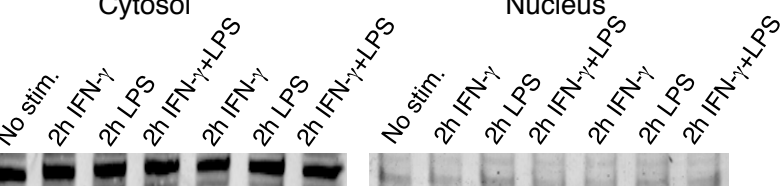
AIM2

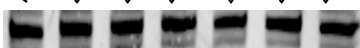
ARTD1

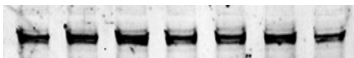

Tubulin

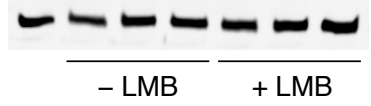

- LMB $\overline{+ \text { LMB }}$ 


\section{Figure 5}

A

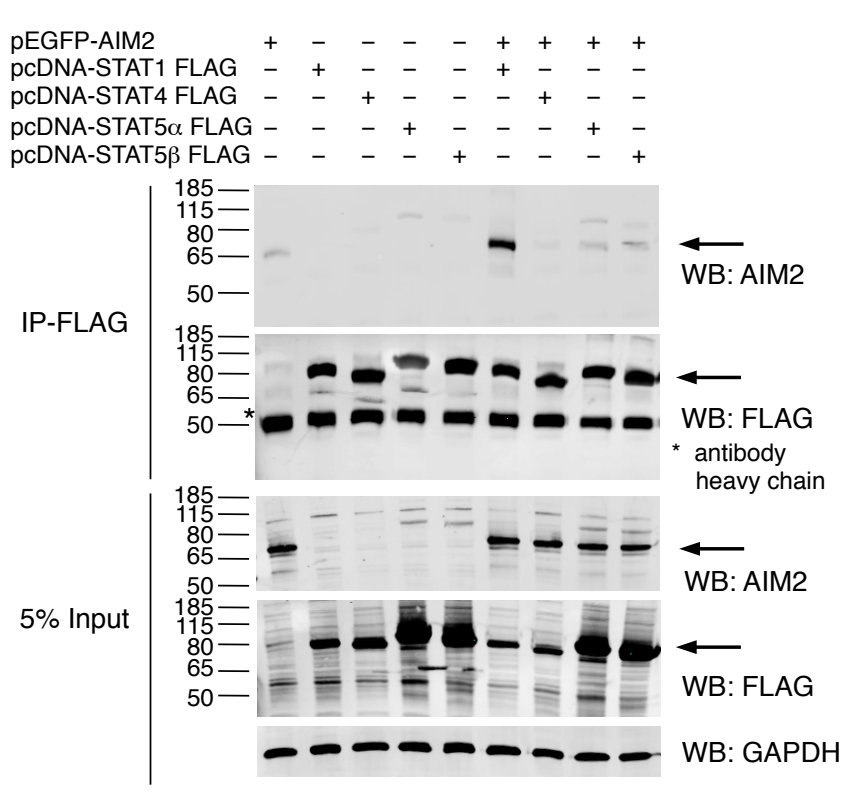

pEGFP-AIM2

$B$

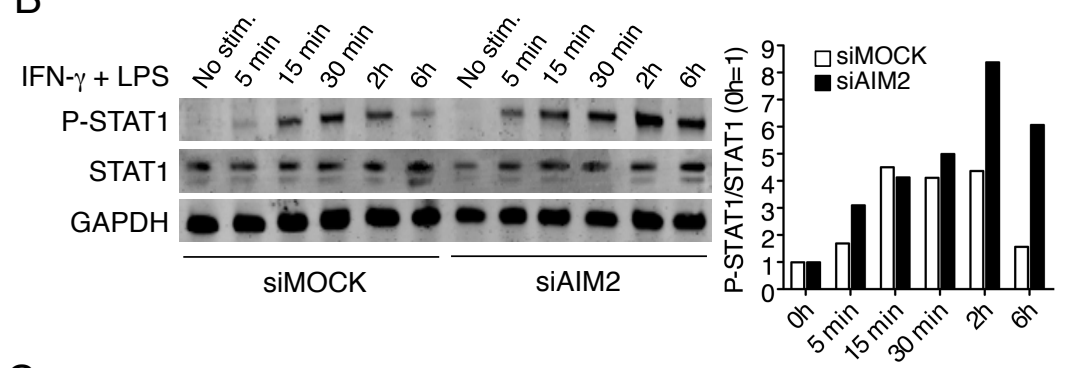

C

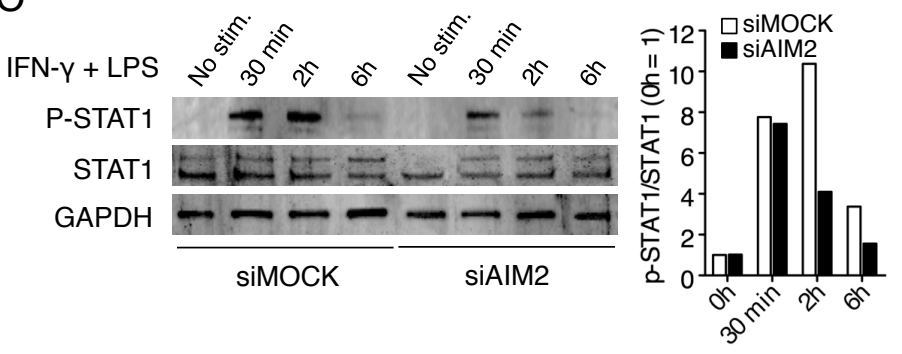

D

E

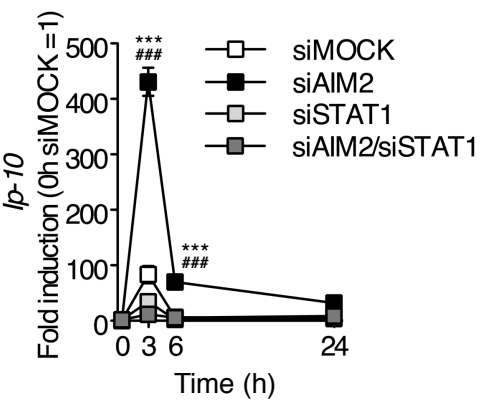

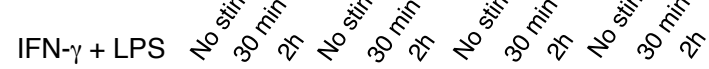
Ac-NF-kB p65 - - - - - - - -

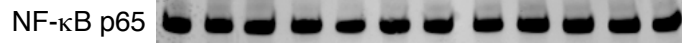
AIM2 $\mathrm{E}=\mathrm{E}=\mathrm{E}=\mathrm{E}=\mathrm{E}$

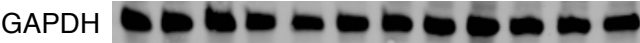

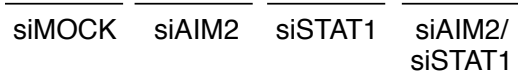
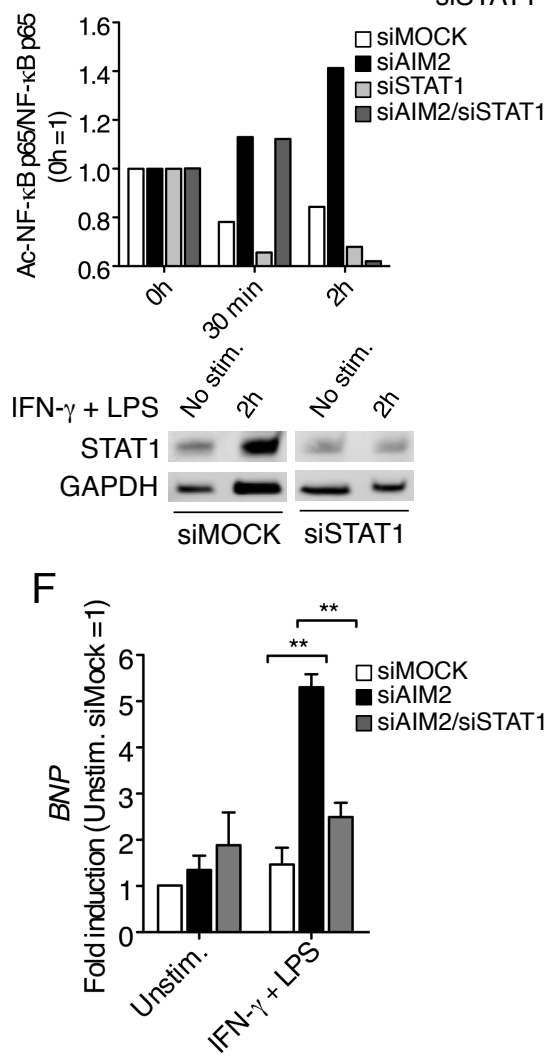